\title{
Home Injuries among Young Children in Malaysia: A Population Based Study
}

Norhafizah Bt. Sahril ${ }^{*}$ Yeo Pei Sien, Mohd Hatta Bt. Abdul Mutalip and Balkish Bt. Mahadir Naidu

Institute for Public Health, National Institutes of Health, Ministry of Health Malaysia

*Corresponding author: Norhafizah, Institute for Public Health, Ministry of Health Malaysia, Jalan Bangsar, 50590 Kuala Lumpur, Malaysia, Tel no: +60322979400; Fax no: +60322823114; E-mail: norhafizah_s@moh.gov.my

Rec date: Jul 13, 2014, Acc date: Oct 01, 2014, Pub date: Oct 10, 2014

Copyright: () 2014, Sahril NB, et al. This is an open-access article distributed under the terms of the Creative Commons Attribution License, which permits unrestricted use, distribution, and reproduction in any medium, provided the original author and source are credited.

\begin{abstract}
Background: Home injury among children is a public health concern. This study aimed to assess the prevalence rate and risk factors of home injury among children less than seven years old in Malaysia.

Methods:Secondary data from National Health and Morbidity Survey 2006 was used. It was a cross sectional study using a stratified two stage sampling technique. The data was analysed using SPSS version 19. Descriptive and multiple logistic regressions were used in the analysis. All tests were two tailed with significance as $p<0.05$. Odds ratio (OR) along with $95 \%$ confidence interval (C.I) were derived where appropriate.

Results:Among 8017 children aged less than seven years, 994 (11.4\%) experienced some kind of home injury within the past one year. Among those who were injured, the higher prevalence was reported among boys; $13.1 \%$ (95\% Cl: 12.00-14.20), rural dwellers; $12.4 \%$ (95\% Cl: $11.20-13.80)$, children aged $0-4$ years old $11.8 \%(95 \% \mathrm{Cl}$ : 10.90-12.80), Indians; $14.7 \%(95 \% \mathrm{Cl}: 11.80-18.20)$ and children from high family incomes. Multiple logistic regression analysis revealed that boys $(a O R=1.424, p<0.001)$, rural dwellers $(a O R=1.243, p=0.015)$, children from ethnic Indians $(a O R=1.949, p<0.001)$, others ethnics $(a O R=1.865, p<0.001)$ and Malays $(a O R=1.427, p=0.007)$ were more likely to sustain a home injury. Children from high $(a O R=1.607, p=0.006)$ and medium (aOR=1.255, $p=0.016$ ) family income were also significantly associated to sustain home injury after adjusting all other predictors. As a result from home injury, about $11.6 \%(95 \% \mathrm{Cl}: 9.7-13.8)$ were unable to perform activities whilst $4.8 \%(95 \% \mathrm{Cl}$ : 3.7-6.3) of them had been admitted to the hospital.
\end{abstract}

Conclusion:Home injury among children is still a health problem which should not be taken lightly. Educational and interventional programs need to be implemented accordingly in order to help Malaysians understand the importance of making a safe home environment for children thus preventing home injuries.

Keywords: Home injuries; Children; National health and morbidity survey; NHMS

\section{Introduction}

Injury to young children is a public health problem. The World Health Organization (WHO) has estimated that around 875,000 children under the age of 18 years old died as a result of injury in 2002. Besides the high rate of death among children, injuries during childhood also associated with high morbidity. It was found that for every dead injured child, there were several thousand more of children who survived with varying degrees of disability [1]

Home is a place where many people spend most of their times. Although the home is perceived to be a safer place, it is found as one of the common location for injury [2]. In New Zealand, home injury represented $41.7 \%$ of all death and $39.1 \%$ of all hospital admission due to non-transport unintentional injury [3]. In addition, an injury surveillance over a one-year period in Norway and study by Swedish Community Survey in Sweden have found that all accidents among children were mostly related to home accidents. Of all the children who has had injuries, the home was the most common place where injuries occurred (45\%) in Singapore [4-6]. According to Canadian Hospital Injury Reporting and Prevention Program (CHIRPP), injuries commonly occurred in child's own home, particularly in children aged 0-4 years [7]. Another study also found that toddlers and pre-school age children had the biggest risk of getting injured in their homes [8].

In Malaysia, home accident was second to road as a place for injury. The National Health Morbidity Survey 1996, a population based on the study done by the Ministry of Health Malaysia have reported that the prevalence of home injury were $2.5 \%$ and it was higher among children (0-4 years old) [9]. Report from the Accidents and Emergency Department of Kuala Lumpur Hospital also had estimated that about $10 \%$ of injuries were sustained at home and those who had been injured were mostly among children [10].There were less research done on home injury compared to road and occupational injuries in Malaysia. Although, some of the studies have showed some piecemeal interest of certain types of injury however, study on home injury among children population less than seven years old has never been done before. Therefore, this study was conducted to assess the prevalence rate and risk factors of home injury among children less than seven years old in Malaysia. 


\section{Material and Methods}

\section{The third national health and morbidity survey (NHMS III, 2006)}

The NHMS 2006 was a national survey and used a sampling frame of the Malaysian Department of Statistics. The country was divided into contiguous geographical areas called Enumeration Blocks (EBs). These EBs constituted the sampling frame for the NHMS 2006. A twostage stratified sample design was used. The first stage sampling unit was the EB and the second stage sampling unit was the Living Quarters (LQ). All household and persons within a selected LQ were included in the survey. The EBs were selected using a probability which was proportionate to a size linear systematic selection scheme based on the latest updated size measurement. The selection of EBs was carried out independently within each state (as a primary stratum) and within urban or rural areas (as secondary stratum) in accordance to the selection rate determined for each stratum. This ensured that the sample size was representative of the population at the national levels.

Field data collection was conducted for four months in 2006. A bilingual (Malays and English) pre-coded questionnaire was designed, pre-tested and piloted prior to the commencements of the survey. Trained research assistant conducted face-to-face interviews with parents or guardians of the children. The complete protocol can be found elsewhere [11].

\section{Sampling}

All children aged less than seven years old who has experienced of home injury in the last one year were selected for the purpose of this study. Parents or guardians were responsible for answering the questions related to home injury on behalf of their children in their homes.

\section{Instrument}

Home injury was part of the module on Injuries that also covered other types of injuries. Home injury was defined as any injuries in the respondent's house and/or 'other house' in the last one year. The questions on home injury were subjected to all children aged less than seven years old who had experienced home injury in the last one year. There were five questions related to home injury that cover on experienced of home injury, location of injury, causes of injury, unable to do activities and hospital admission due to injuries.

For experience of home injury, respondents were asked if they had any history of home injury for the past one year with a possible one categorical answer $(1)=$ Yes, $(2)=$ No and (3)=Refuse to answer. For location of injury, respondent were asked the location of injury occurrence with possible multiple categorical answer $(1)=$ Compound, (2)=Driveway, (3)=Drain, (4)=Living room, (5)=Bedroom, (6)=Kitchen, (7)=Bathroom, (8)Stairs, (9)=Swimming pool, $(10)=$ Store, $\quad(11)=$ Attic/Roof, $(12)=$ Balcony, $(13)=$ Under the house, $(14)=\mathrm{Lift}$ and $(15)=$ Others. Respondents were also asked about the three most common causes of the injuries with possible multiple categorical answer $(1)=$ Fall, $(2)=$ Struck by object, ( 3$)=$ Cut, $(4)=$ Hit by person, (5)=Caught in between object(s), (6)=Fire/flames or heat, (7)=Near drowning, (8)=Poisoning, (9)=Animal bite, (10)=Electricity shock, (11)=Foreign body (ies) entering natural orifices, $(12)=$ Suffocation,$\quad(13)=$ Stab,$\quad(14)=$ Gunshot $\quad$ and $\quad(15)=$ Others . Question on inability to do the activities was asked whether respondents were unable to go to school or play as a result of injuries with one possible categorical answer (1)=Yes, (2)=No and (3)=Refuse to answer. The last question was on hospital admission where respondents were asked whether they were admitted to the hospital because of any injuries with a possible one categorical answer (1)=Yes, $(2)=$ No and $(3)=$ Refuse to answer.

\section{Data analysis}

Data analyses were conducted using SPSS version 19.0 utilising complex survey design. Descriptive analyses were used to estimate the prevalence of overall home injury among children less than 7 years old in Malaysia and prevalence by socio-demography profiles. Descriptive analyses also were done to estimate the causes, place and outcome of home injuries. A multiple logistic regression modelling was applied to analyse the odds of home injury by socio-demography predictors for residency, sex, age group and family income. Final model was created that include all predictors and interactions which were significantly associated at a level of $\mathrm{p}$-value $<0.05$.

\section{Results}

There were 8017 eligible children aged less than seven years old in this study. More than half of them $(62.1 \%)$ resided in urban areas. The majority of them were boys; $51.4 \%$. By ethnicity, the majority were Malays; $60.8 \%$ followed by others ethnic; $17.2 \%$, Chinese; $14.9 \%$ and Indians; $7.3 \%$. In terms of age groups, the majority of the children were aged $0-4$ years old $(68.6 \%)$. The majority of children were from medium family income (MYR1000-4999); $58.5 \%$, followed by a low family income (less than MYR1000); 33.5\% and a high family income (more than MYR5000); 8.1\%.

$994(11.4 \%)$ of the children were reported of experiencing at least one injury in the last one year. The prevalence of home injuries were reported higher among boys; $13.1 \%$ (95\% CI: 12.00-14.20), rural dwellers; $12.4 \%$ (95\% CI: 11.20-13.80), children aged 0-4 years old; $11.8 \%$ (95\% CI: 10.90-12.80), Indians; $14.7 \%$ (95\% CI: $11.80-18.20$ ) and children from high family income; $13.2 \%$ (C.I: 10.2-16.8).

Multiple logistic regression analysis revealed that boys $(\mathrm{aOR}=1.424$, $\mathrm{p}<0.001)$, rural dwellers $(\mathrm{aOR}=1.243, \mathrm{p}=0.015)$, children from ethnic Indians $(\mathrm{aOR}=1.949, \mathrm{p}<0.001)$, others ethnics $(\mathrm{aOR}=1.865, \mathrm{p}<0.001)$ and Malays $(\mathrm{aOR}=1.427, \mathrm{p}=0.007)$ were more likely to sustain a home injury. Children from high $(\mathrm{aOR}=1.607, \mathrm{p}=0.006)$ and medium $(\mathrm{aOR}=1.255, \mathrm{p}=0.016)$ family income were also significantly associated to sustain home injury after adjusting all other predictors (Table 1).

Among those who had injuries, 11.6\% (95\% CI: 9.7-13.8) of them were unable to perform activities after the injury and 4.8\% (95\% CI: 3.7-6.3) were reported to be admitted to hospital.

The three most common causes of injury were fall 10.3\% (95\% CI: 9.6-11.2), followed by cut $0.4 \%$ (95\% CI: $0.3-0.5$ ) and struck by objects $0.2 \%$ (95\% CI: $0.2-0.4)$. The most common injury location reported were in the compound $44.2 \%$ (95\%CI: 40.6-47.7), living room $34.0 \%$ (95\% CI: 30.7-37.5), bedroom 9.3\% (95\% CI: 7.4-11.6), kitchen $8.8 \%$ (95\% CI: 7.0-10.9) and stairs 8.3\% (95\% CI: 6.7-10.4). 


\begin{tabular}{|c|c|c|c|c|c|c|c|}
\hline \multirow{2}{*}{ Variable } & \multicolumn{3}{|c|}{ No. $(\%)$ of respondents } & Crude OR & $p$-value & \multirow{2}{*}{ Adjusted OR } & \multirow{2}{*}{$p$-value } \\
\hline & Total & Injury & No Injury & & & & \\
\hline \multicolumn{8}{|l|}{ Sex } \\
\hline Male & $4419(51.4)$ & $587(13.1)$ & $3817(86.9)$ & 1.423 & $<0.001$ & 1.424 & $<0.001$ \\
\hline Female & 4198 (48.6) & $407(9.6)$ & 3777 90.4) & 1 & & 1 & \\
\hline \multicolumn{8}{|l|}{ Residence } \\
\hline Urban & $4866(62.1)$ & $526(10.7)$ & 4318(89.3) & 1 & & 1 & \\
\hline Rural & 3751 (37.9) & $468(12.4)$ & $3276(87.6)$ & 1.181 & 0.046 & 1.243 & 0.015 \\
\hline \multicolumn{8}{|l|}{ Age Group } \\
\hline $0-4$ years old & $5909(68.6)$ & $703(11.8)$ & $5187(88.2)$ & 1.135 & 0.091 & 1.144 & 0.077 \\
\hline $5-6$ years old & 2708 (31.4) & $291(10.5)$ & $2407(89.5)$ & 1 & & 1 & \\
\hline \multicolumn{8}{|l|}{ Ethnicity } \\
\hline Malays & $5210(60.8)$ & $587(11.2)$ & $4611(88.8)$ & 1.42 & 0.005 & 1.427 & 0.007 \\
\hline Chinese & $1193(14.9)$ & $97(8.2)$ & $1090(91.8)$ & 1 & & 1 & \\
\hline Indian & $585(7.3)$ & $86(14.7)$ & 495 (85.3) & 1.936 & $<0.001$ & 1.949 & $<0.001$ \\
\hline Others & $1629(17.2)$ & $224(13.3)$ & 1398(86.7) & 1.716 & $<0.001$ & 1.865 & $<0.001$ \\
\hline \multicolumn{8}{|c|}{ Household-Income (Malaysia Ringgit) } \\
\hline $\begin{array}{l}\text { Low } \\
(<M Y R 1000)\end{array}$ & $2961(33.5)$ & $319(10.7)$ & $2630(89.3)$ & 1 & & 1 & \\
\hline $\begin{array}{l}\text { Medium } \\
\text { (MYR1000-4999 } \\
\text { ) }\end{array}$ & $4746(58.5)$ & $565(11.7)$ & $4168(88.3)$ & 1.15 & 0.248 & 1.255 & 0.016 \\
\hline $\begin{array}{l}\text { High } \\
\text { (>MYR5000) }\end{array}$ & $624(8.1)$ & $83(13.2)$ & $537(7.0)$ & 1.267 & 0.142 & 1.607 & 0.006 \\
\hline
\end{tabular}

Table 1: Risk factors of home injury among children less than seven years old

\section{Discussion}

Children represent one of the vulnerable groups for injuries. Home is perceived to be a safer place, but it witnessed scenes of numerous injuries among young children [2]. The results of this study indicated that $11.4 \%$ of children aged below than seven years old reported to have experience home injury. The higher prevalence of home injury were among boys, rural dwellers, children aged 0-4 years old, Indians and children from high family incomes. Boys, rural dwellers, Indians, Malays, others ethnic and children from high and medium family income were statistically significant to sustain home injury by multiple logistic regressions.

Majority of injuries occur in home were among children aged 0-4 years old $[7,12]$. Study in Israel also have found that children of $0-4$ years old have the most accidents at home and boys were more likely to have accidents than girls [2]. The risk and types of injuries suffered are strongly associated with sex. For almost all types of childhood injury, boys were found at higher risk for injuries than girls $[13,14]$. The difference between boys and girls may be related to traditional males and females roles. Differences in socialisation operating at early age may also result in differences in risk-taking behaviours between boys and girls $[14,15]$. Previous study done by Morrongiello et.al has found that injury rates were associated with supervision. The findings showed that injury rates for boys and girls differed significantly when mothers used the strategy of intermittently going to check on the child, with boys experiencing more injuries than girls $(\mathrm{p}<0.05)$. In fact, injury rates for boys when mothers intermittently listened in were as high as when mothers left their sons unsupervised, and rates for girls were as low as when mothers provided direct and close supervision [16].

In Singapore, home accidents were the most common of injury (56.4\%) among children. Children aged less than five years old were reported to be more likely to sustain home injuries $(\mathrm{p}<0.0001)[17]$. Previous study done by Zaleha et al. in 1994 has found that $24.7 \%$ children below six years old experienced home injury in community level in Malaysia and Indians children were also reported of higher rate of being injured compared to the Malays and Chinese [18]. Several researchers have found that ethnicity was a less important factor than income and other socioeconomics variables in predicting child injury rate $[19,20]$. Some demographic characteristics such as 
ethnicity could be a marker for other underlying factors such as poverty and education and social disadvantage were also found to be more important than ethnicity as a determinant of home accidents to children $[21,22]$.

Accidents among children were related to social economic status [23]. Although many literatures showed that children in families with lowest income were more prone to accidents at home, it was the opposite than this study has found [24,25]. It seems that when parents had higher incomes, their children have higher risks of injuries at home. That could be because the majority of parents in Malaysia are working and factors of tiredness when coming back from work could be contributed to lack of supervision to their children. Insufficient supervision during the children's playing also will double the cause of injury [26]. At younger ages, the mere presence in the home of a parent, even one not directly supervising, often deters risk behaviours, and direct supervision can significantly reduce the risk of injury to children who have temperamental attributes that increase their injury risk $[16,27,28]$. Hence, because young children are often in the vicinity of potential supervisors, this may reduce the relative impact child behaviour attributes have on their risk of injury.

It was saddening to note that about $11.6 \%$ of children were unable to perform activities after sustaining the injuries and $4.8 \%$ of them were admitted to the hospital in this study. Although the numbers of children affected were small, it is important to prevent unintentional injury among children since it is remaining one of the main threats to health of children [29]. The World Health Organization Report 2008 has reported that about 10 millions of children required hospital care for non-fatal injuries every year and many were left with lifelong disabilities [30]. The impact of injury was not only affecting the children, but it also can increase burden to the family, society and the nation.

Fall was found the most common causes of injury in this study, followed by cut and struck by objects. Falls are the second leading cause of accidental or unintentional injury death worldwide and falls are usually reported to be the most common cause of injury seen in hospital, accounting for $25 \%$ to $52 \%$ of all treated child injuries [30-32]. Fall-related injuries were found to affect children during their early stage of development and injuries were usually occurred at home $[31,33]$.In Greece, almost two-third of all injuries among infants were also reported due to fall [34]. Previous National Health Morbidity Survey 1996 also has found that cut was the second most common mechanism of home injury after falls and majority involved were children [9]. Study done by Syed Hasan Mawas et al. had found that children under five years old in India were more prone to fall $(32.4 \%)$ and struck by objects (32.4\%) in comparison to children aged 6-15 years old [35]. Another finding by J.B Kotch et.al also has found that the most common types of injury among children in North Carolina were due to fall and being struck by objects [36].

Compound, living room, bedroom, kitchen and stairs were the five most common locations of injuries. This finding is supported by studies done by Zaleha et.al whereby the most frequent location of injury among children were in living room (59.6\%), followed by kitchen $12.8 \%$ and compound $10.6 \%$ [18].The study about childhood injuries in Singapore also showed similar findings with ours, in which the most common injuries occurred was in the living room ,kitchen, bedroom and bathroom with falls as the most common type of injury [6]. In the United States, stairs was a common source of injury to children and during the 10 years study period from 1999 to 2008, it was found that an estimated of 931,886 children aged less than five years old were treated in United States Emergency Departments were due to stairs-related injuries and $94.2 \%$ of the injury occurred in children's home[37]. In New Zealand, children aged less than five years old also were found more likely to fall inside the house with large proportion involving stairs [35]. Another study done by John C et al. had found that among 177 falls sustained by children, $104(58.8 \%)$ occurred at stairs [38]. In Karachi of Pakistan, almost one-third of injuries among children took place in the kitchen [39]. Every year more than 67,000 of children experienced an accident in the kitchen with 43,000 of these involved children at age between 0-4 years; while about 58,000 of children have an accident on the stairs[18]. Caregiver supervision may be one of the contributing factors to injury risk for young children. Children without supervision were found to be more often to get injured in the living room, kitchen, bathroom and bedroom [40].

Children have the right to a healthy, safe environment and protection from injury. Parents or caregiver play an important role in supervising their children and also their responsibility is to make the environment of the house safe for their children. Parents must assume responsibility for the safety of younger aged children in view of their limitation during the developmental stages in avoiding risks and differentiating safe-unsafe situations [41]. This is in concomitant with many studies that documented lack of supervision is associated with increased risk of injuries for young children [42]. A major focus in future research need to be directed on developing injury prevention programs targeting parental supervisory practices. In order to prevent injuries during childhood, full range of approaches such as education, environmental modification and improving regulation and legislation need to be implemented. Henceforth, child injury prevention should be a responsibility shared by multiple components; government and non-governmental organizations, international agencies, academic institutions and also the business sectors.

\section{Limitation}

This study utilized secondary data from the NHMS 2006 study. Data was gathered from self-reporting and not verified from any records which were found as a limitation in this study. Further research should be undertaken in depth to describe more detail on factors that might be associated with home injury such as home hazards, parent supervisions and children's behaviour.

\section{Conclusion}

Childhood injuries are indeed a growing public health problem which deserves more attention than being currently given. There is a need for educational and intervention programmes to increase the awareness and understanding of child safety and injury prevention in Malaysia and to make the home a safe environment for children.

\section{Completing interest}

The authors declare that they have no completing interests.

\section{Authors' contribution}

NS: Set the objective, study design, analysis and interpretation of the data, and drafted the manuscript.

YPS: Involve in study design and drafted the manuscript

HM: Involve in study design and drafted the manuscript 
BMN: Involve in study design and drafted the manuscript

\section{Acknowledgement}

The authors would like to thank the Director General of Health Malaysia, for his permission to publish this paper.

\section{References}

1. World Health Organization Report (2005) Child and adolescent injury prevention: A global to action.

2. Sikron F, Giveon A, Aharonson-Daniel L, Peleg K (2004) My home is my castle! Or is it? Hospitalizations following home injury in Israel, 1997-2001. Isr Med Assoc J 6:332-335.

3. Bandaranayake D, Salmond C, Kljakovic M, Borman B (1990) Domestic unintentional injuries presenting to the accident and emergency departments in the Wellington region. N Z Med J 103:528-531.

4. Sahlin Y, Stene TM, Lereim I, Balstad P (1990) Occurrence of injuries in a defined population. Injury 21:155-157.

5. Jacobsson B, Schelp L (1987) Home accidents among children and teenagers in a Swedish rural municipality. Scandinavian Journal of Public Health 15:31-35.

6. Thein MM, Lee BW, Bun PY (2005) Childhood injuries in Singapore: a community nationwide study. Singapore medical journal 46: 116-121.

7. Morrison A, Stone D H, Doraiswamy N, Ramsay L (1999) Injury surveillance in an accident and emergency department: a year in the life of CHIRPP. Arch Dis Child 80:533-536

8. Shannon A, Brashaw, B, Lewis J, Feldman W (1992) Nonfatal childhood injuries: A survey at the Children's Hospital of eastern Ontario. CMAJournal 146:361-365.

9. Institute For Public Health, Ministry of Health Malaysia (1996). National Health And Morbidity Survey Report (NHMS II).

10. Che Ros M.N (1994) Injury control and promotion of safety: A challenge for all sectors. In Proceeding of Seminars on Injury Control and Promotion of Safety: Education and Research 1994, Kuala Lumpur.

11. Institute For Public Health Ministry of Health Malaysia (2006). The Third National Health And Morbidity Survey Report 2006 (NHMS III).

12. Downswell T, Towner E (2002) Social deprivation and the prevention of unintentional injury in childhood: a systematic review. Health Education Research 17:221-237

13. Laflamme L, EilertPetersson E (1998) Injuries to preschool children in a home setting: patterns and related products. Acta Paediatr 87:206-211.

14. Morrongiello BA, Rennie H (1998) Why do boys engage in more risk taking than girls? The role of attributions, beliefs, and risk appraisals. Journal of Pediatric Psychology 23:33-43.

15. Morrongiello BA, Rennie H (1998) Toddlers' and mothers' behaviour in an injury-risk situation: implications for sex differences in childhood injuries. J. Appl. Dev. Psychol. 19:625-639

16. Morrongiello BA, Ondejko L, Littlejohn A (2004) Understanding toddlers' in-home injuries: II. Examining parental strategies, and their efficacy, for managing child injury risk. J. Pediatr. Psychol. 29:433-446.

17. Ong M, Ooi S, Manning P (2003) A review of 2,517 childhood injuries seen in a Singapore emergency department in 1999: mechanisms and injury prevention suggestions. Singapore medical journal 44(1):12-19.

18. Zaleha MSS (1994) Home accidents among children below 6 years in Taman Soga, Batu Pahat, Johor. Thesis for Masters in Community Health. Universiti Kebangsaan Malaysia.

19. Gielen AC, Wilson ME, Faden RR, Wissow L, Harvilchuck JD (1995) Inhome injury prevention practices for infants and toddlers: the role of parental beliefs, barriers, and housing quality. Health Educ Q. 22(1): 85-95.

20. Bishai D, McCauley J, Trifiletti LB, McDonald EM, Reeb B et al. (2002) The burden of injury in preschool children in an urban medicaid managed care organization. Ambul Pediatr 2:279-283.
21. Grossman DC (2000) The history of injury control and the epidemiology of child and adolescent injuries. Future Child 10:23-52.

22. Alwash R, McCarthy M (1988) Accidents in the home among children under 5: ethnic differences or social disadvantage? Br Med J (Clin Res Ed) 296:1450-1453.

23. MacKay M, Reid DC, Moher D, Klassen T (2001) Systematic review of the relationship between childhood injury and socio-economic status: Health Canada

24. Reading R, Langford IH, Haynes R, Lovett A (1999) Accidents to preschool children: comparing family and neighbourhood risk factors. Soc Sci Med 48:321-330.

25. Dowswell T, Towner EM, Simpson G, Jarvis SN (1996) Preventing childhood unintentional injuries--what works? A literature review. In Prev 2:140-149.

26. Wazana A (1997) Are there injury-prone children? A critical review of the literature. Can Journal Psychiatry 42:602-610.

27. Morrongiello BA, Klemencic N, Corbett M (2008) Interactions between child behavior patterns and parent supervision: Implications for children's risk of unintentional injury. Child Dev 79:627-638.

28. Schwebel DC, Bounds ML (2003) The role of parents and temperament on children's estimation of physical ability: Links to unintentional injury prevention. J Pediatr Psychol 28:505-516.

29. Sibert JR (1991) Accidents to children: the doctor's role. Education or environmental change? Arch Dis Child 66:890-893.

30. Peden M (2008) World report on child injury prevention appeals to "Keep Kids Safe". Inj Prev 14:413-414.

31. Bangdiwala SI, Anzola-Perez E, Romer CC, Schmidt B, Valdez-Lazo FT, et al.(1990) The incidence of injuries in young people: I methodology and results of a collaborative study in Brazil, Chile, Cuba and Venezuela. Int Journal Epidemiol 19:115-124.

32. Bener A, El-Rufaie O, Al-Suweidi N (1997) Pediatric injuries in an Arabian Gulf country. Inj Prev 3:224-226.

33. Ruangkanchanasetr S, Sriwatanakul K, Luptawan S, Prapat-tong S (1991) Epidemiology and risk factors of injury in Thai children. Southeast Asian J Trop Med Public Health 22:127-132.

34. Dedoukou X, Spyridopoulos T, Kedikoglou S, Alexe DM, Dessypris N, et al. (2004) Incidence and risk factors of fall injuries among infants: a study in Greece. Arch Pediatr Adolesc Med 158:1002-1006.

35. Zaidi SHN, Khan Z, Khalique N (2013) Injury pattern in children: a population-based study. Indian Journal of Community Health (IJCH) 1 : 45-51.

36. Kotch JB, Dufort VM, Stewart P, Fieberg J, McMurray M, et al.(1997) Injuries among children in home and out-of-home care. Inj Prev 3:267-271.

37. Zielinski AE, Rochette LM, Smith GA (2012) Stair-Related Injuries to Young Children Treated in US Emergency Departments, 1999-2008. Pediatrics 129:721-727.

38. LeBlanc JC, Pless IB, King WJ, Bawden H, Bernard-Bonnin AC, et al. (2006) Home safety measures and the risk of unintentional injury among young children: a multicentre case-control study. CMAJ 175: 883-887.

39. Razzak JA, Luby S, Laflamme L, Chotani H (2004) Injuries among children in Karachi, Pakistan-what, where and how. Public Health 118:114-120.

40. Morrongiello BA, Corbett M, McCourt M, Johnston N (2006) Understanding unintentional injury-risk in young children I. The nature and scope of caregiver supervision of children at home. J Pediatr Psychol 31: 529-539.

41. Morrongiello BA, Mcarthur BA (2010) Parent Supervision to Prevent Injuries. Parenting Skills. Encyclopedia on Early Childhood Development.

42. Morrongiello BA, Corbett M, Brison RJ (2009) Identifying predictors of medically-attended injuries to young children: do child or parent behavioural attributes matter? Inj Prev 15: 220-225. 